Fixed Point Theory, 19(2018), No. 2, 625-630

DOI: $10.24193 /$ fpt-ro.2018.2.49

http://www.math.ubbcluj.ro/ ${ }_{\text {nodeacj/sfptcj.html }}$

\title{
ON THE CLASS OF RELATIVELY WEAKLY DEMICOMPACT NONLINEAR OPERATORS
}

\author{
BILEL KRICHEN* AND DONAL O'REGAN** \\ *Department of Mathematics, \\ Faculty of Sciences of Sfax, University of Sfax, \\ Road Soukra Km 3.5 B.P. 1171, 3000, Sfax Tunisia \\ E-mail: krichen_bilel@yahoo.fr \\ ${ }^{* *}$ School of Mathematics, National University of Ireland \\ Galway, Ireland \\ E-mail: donal.oregan@nuigalway.ie
}

Abstract. In this paper we discuss some topological properties of the set

$$
\mathcal{F}\left(S_{0}, T, z\right):=\left\{x \in X: S_{0} x \in T x+z\right\},
$$

where $T$ is a nonlinear multi-valued mappings and $S_{0}$ is a single-valued mappings acting on a Banach space $X$. This study is based on a new concept, the so called weakly relative demicompactness for nonlinear operators.

Key Words and Phrases: Demicompact operator, multi-valued mapping, weak topology, measure of weak noncompactness.

2010 Mathematics Subject Classification: 58C07, 47H04.

\section{REFERENCES}

[1] W.Y. Akashi, On the perturbation theory for Fredholm operators, Osaka J. Math., 21(1984), 603-612.

[2] J. Appell, E. De Pascale, Su alcuni parametri connessi con la misura di non compattezza di Haussdorff in spazi di funzioni misurabili, Boll. Unione Mat. Ital. Sez. B, 6(1984), 497-515.

[3] Z. Artstein, Continuous dependence of solutions of operator equations, Trans. Amer. Math. Soc., 231(1977), no. 1, 143-166.

[4] J. Banas, J. Rivero, On measures of weak noncompactness, Ann. Mat. Pura Appl., 151(1988), 213-224.

[5] W. Chaker, A. Jeribi, B. Krichen, Demicompact linear operators, essential spectrum and some perturbation results, Math. Nachr., 288(2015), 1476-1486.

[6] F.S. De Blasi, On a property of the unit sphere in a Banach space, Bull. Math. Soc. Sci. Math. R.S. Roumanie, (N.S.), 21(1977), 259-262.

[7] L. Gorniewicz, Topological Fixed Point Theory of Multivalued Mappings, Springer, Berlin, 2009.

[8] A. Jeribi, B. Krichen, Nonlinear Functional Analysis in Banach Spaces and Banach Algebras: Fixed Point Theory under Weak Topology for Nonlinear Operators and Block Operator Matrices with Applications, Monographs and Research Notes in Mathematics, CRC Press Taylor and Francis, 2015. 
[9] B. Krichen, Relative essential spectra involving relative demicompact unbounded linear operators, Acta Math. Sci. Ser. B Engl., 34(2014), 546-556.

[10] E. Megginson, Robert, An Introduction to Banach Space Theory, Graduate Texts in Mathematics, Springer Verlag, 1988.

[11] Z. Opial, Nonexpansive and monotone mappings in Banach spaces, Center for Dynamical Systems, Brown Univ, Providence, R.I, 1967, 1-67.

[12] W.V. Petryshyn, Construction of fixed points of demicompact mappings in Hilbert space, J. Math. Anal. Appl., 14(1966), 276-284.

[13] W.V. Petryshyn, Remarks on condensing and k-set-contractive mappings, J. Math. Anal. Appl., 39(1972), 717-741.

[14] W.V. Petryshyn, Structure of the fixed points sets of k-set-contractions, Arch. Rational Mech. Anal., 40(1971), 312-328.

Received: January 14, 2016; Accepted: March 12, 2016. 